Kompetente Antworten innerhalb von 48 Stunden! Unsere Experten, Prof. H. S. Füeßl und Dr. med. P. Stiefelhagen, beantworten medizinische Fragen, die sich in Ihrem Praxisalltag ergeben.
Hier erhalten Sie Rat

bei kniffligen Fällen:

www.springermedizin.de/ mmw-sprechstunde
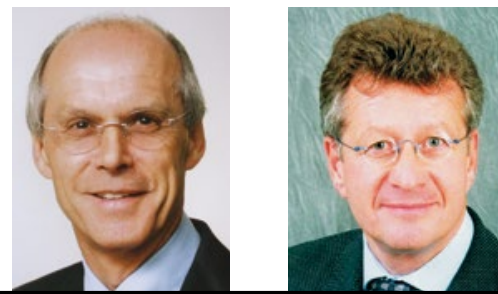

Dr. med. P. Stiefelhagen

Internist,

Hachenburg

Kardiovaskuläres Risiko

\title{
Soll man lieber rauchen oder fett werden?
}

\section{? Frage von Dr. M. L.: Ich habe einen 55-jährigen Patienten, der vor einem halben Jahr erfolgreich aufge- hört hat zu rauchen. Bei seinem letz- ten Praxisbesuch klagte er über eine starke Gewichtszunahme seit dem Rauchstopp - sein aktueller Body- Mass-Index (BMI) lag bei $30,3 \mathrm{~kg} / \mathrm{m}^{2}$ - und fragte mich, was sein kardiovas- kuläres Risikos am stärksten steigert: Weiterrauchen oder die Gewichtszu- nahme. Gibt es hierzu Studien bzw. valide Untersuchungen?} nächst einmal gilt es, mit einem Mythos aufzuräumen: Der Nikotinverzicht selbst führt nicht zu der Gewichtszunahme, sondern das Aufhören mit dem Rauchen wird meist vom Patienten selbst mit einer vermehrten Kalorienaufnahme belohnt. Also kann man durch Sport und eine Veränderung der Ernährungsgewohnheiten gegensteuern. Auch muss der Patient wissen, dass es beim Nikotinverzicht nicht nur um das kardiovaskuläre Risiko geht, sondern auch um die Verhinderung einer COPD und des Bronchialkarzinoms. Ex-Raucher nehmen während der Nikotinabstinenz um 3-5 kg zu, bei ca. $10 \%$ sind es sogar mehr als $15 \mathrm{~kg}$. Nur der geringere Teil ist auf eine zentralnervöse
Wirkung des Nikotins zurückzuführen, der größere Teil des Effekts beruht auf einer Wiederkehr des Geschmackssinns. Gleichzeitig wird die Kalorienaufnahme durch Essen als orale Ersatzhandlung gesteigert.

Diese bekannte Entwicklung führt bei Rauchern zu der Frage an den Arzt, ob sie nicht weiter rauchen sollten, um Übergewicht zu vermeiden. Wasser auf die Mühlen der Nikotinfreunde war v.a. eine Studie aus dem Karolinska Institut von 2009, in der die Mortalität von etwa 46.000 Wehrpflichtigen in Bezug auf BMI und Rauchverhalten zwischen 18 und 38 Jahren untersucht wurde. In diesem Zeitraum verstarben vor allem diejenigen Männer, die mit 18 Jahren zu dick waren. Männer mit einem BMI von $>30 \mathrm{~kg} / \mathrm{m}^{2}$ wiesen eine ähnliche Erhöhung der Mortalität auf wie Männer, die zehn Zigaretten pro Tag rauchten. Wer übergewichtig war und zusätzlich stark rauchte, hatte allerdings ein fünfmal so hohes Risiko, früher zu sterben, als normalgewichtige Nichtraucher.

Raucher wissen um die Gesundheitsschädlichkeit ihres Verhaltens, können aber aufgrund ihres Suchtverhaltens nicht davon lassen - und greifen zur Entschuldigung gerne zum Mittel der Bagatellisierung. Da kommt so eine Studie doch wie gerufen.

Neben der äußerst fraglichen Wirkung auf das Übergewicht, das auch durch gesundheitsfördernde Maßnahmen wie Steigerung der körperlichen Aktivität und Diät angegangen werden kann, nimmt man durch das Rauchen eine Fülle an Nachteilen in Kauf: die Erhöhung der kardiovaskulären Morbidität und Mortalität, die Probleme der Lungengesundheit von Asthma, COPD bis zum Bronchialkarzinom für sich und seine nähere Umgebung, die Steigerung des Risikos für Karzinome von Harnblase, Niere, Kolon, Ösophagus und Pankreas und die potenzielle Schädigung der Nachkommenschaft bei Frauen.

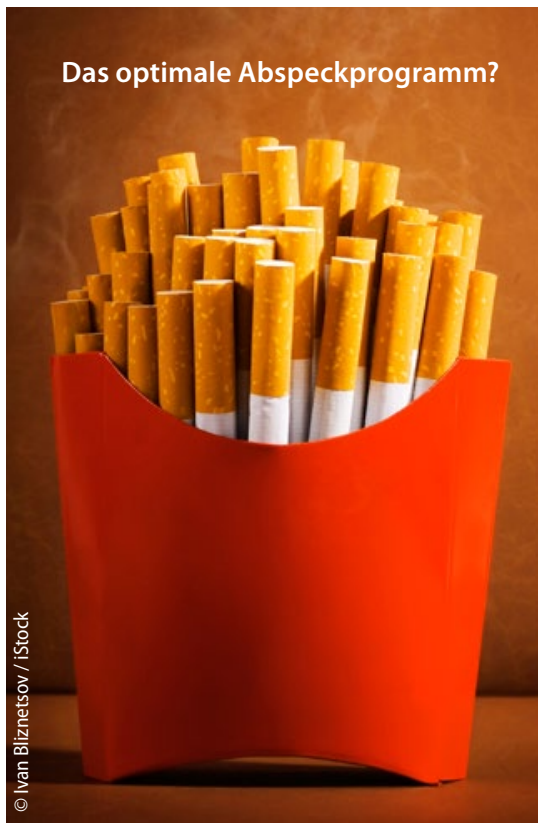

